\title{
Antimicrobial resistance and integron gene cassette arrays in commensal Escherichia coli from human and animal sources in IRI
}

\author{
Roohollah Kheiri ${ }^{*}$ and Leili Akhtari ${ }^{2}$
}

\begin{abstract}
Background: The human and animal intestinal tract harbors a complex community of microbes which enables bacteria to inherit antibiotic resistance genes. The aims of this study were to investigate clonality, antimicrobial resistance, prevalence and gene cassette arrays of class I and II integrons among commensal Escherichia coli from human and animals.
\end{abstract}

Methods: A total of 200 E. coli isolates from human, chicken, cattle, and sheep were isolated followed by phenotypic antibiotic susceptibility testing and detection of class I and II integrons gene cassettes arrays. The clonal relationship of the isolates were analyzed by $(\mathrm{GTG})_{5}-\mathrm{PCR}$.

Results: Of 200 isolates, 136 isolates were multi drug resistance (MDR) including 47, 40, 31 and 18 isolates from chicken, human, cattle and sheep, respectively. Class I integron was detected in 50, 38, 6 and $16 \%$, while class II was detected in 26, 8, 0 and $4 \%$ of chicken, human, cattle and sheep isolates, respectively. Variable regions were amplified and sequenced. Cassette arrays in class I integrons were: dfrA1, dfrA5, dfrA7, dfrA12, aadA1, dfrA17 aadA1, aadA22, aadB-aadA2 and dfrA12-orff-aadA2, and for class II, dfrA1-sat-aadA1, and sat-sat1-aadA1 were detected. Six class I and three class II positive strains did not produce any amplicons for variable region. Integron-positive isolates showed higher rate of resistance to streptomycin and trimethoprim-sulphamethoxazole, especially in chicken isolates which were fed antibiotics. Low similarity and great genetic diversity of class I and II integrons carrying isolates indicated no clonal relation.

Conclusions: Integrons encoding for antibiotic resistance are significantly present among non-pathogenic commensal E. coli, especially from the hosts medicated by antibiotics. Uncontrolled use of antibiotics will increase the numbers of multiple drug resistant isolates and integrons prevalence.

Keywords: Antimicrobial resistance, Escherichia coli, Gene cassette, Integrons

\section{Background}

Escherichia coli is a major member of the human and animal gut's normal microflora. Although commensal $E$. coli strains are non-pathogen, pathogenic types of $E$. coli including enterotoxigenic (ETEC), enterohemorrhagic (EHEC), enteroaggregative (EAEC), enteroinvasive (EIEC), and enteropathogenic (EPEC) can cause intestinal diseases [1].

\footnotetext{
*Correspondence: r_kheirik@yahoo.co.uk

${ }^{1}$ Molecular Microbiology, Quality Control Office, Alborz Province Water and Wastewater Company, Karaj, Alborz, Islamic Republic of Iran Full list of author information is available at the end of the article
}

Carrying resistance plasmids and the ability of transferring resistance, E. coli is a potential reservoir for antimicrobial resistance genes which plays an important role in the ecology of antimicrobial resistance of bacterial populations [2]. In addition, enteric fecal flora from food producing animals such as chicken, cattle and sheep may transfer antimicrobial resistance to human pathogens [3]. Exposure to resistant bacteria via the food-chain has gained increased attention because the presence of resistant bacteria in food and water might have an impact on the development and dissemination of antibiotic resistance among human bacterial pathogens [3]. Followed 
by receiving antibiotics, the emergence of $E$. coli isolates with multiple antibiotic-resistant phenotypes, involving resistance to various families of antibiotics, has been previously reported and it has been suggested that resistance in bacterial populations may spread from one ecosystem to another by lateral gene transfer, specifically integrons [4]. Integrons are bacterial genetic elements that allow the shuffling of smaller mobile elements called gene cassettes; they have been termed 'a genetic construction kit for bacteria [5]. Integrons are involved in the evolution and spreading of antibiotic-resistance genes in enteric bacteria. The amino acid sequences of the integrases have been used as a basis for dividing integrons into 'classes', with those carrying intI1 defined as 'class I', intI2 as 'class II', intI3 as 'class III', etc. Classes of integrons are widely found in gram-negative bacteria and are associated with the spread of antimicrobial drug resistance throughout the world. Therefore, isolates carrying integrons, can survive if exposed to antibiotics [6]. This mostly happens in clinical and veterinary isolates, which will lead to resistance dissemination and failure of treatments. Apart from being carried by clinical strains, studies have reported the occurrence of integrons and gene cassettes in the enteric faecal flora of humans and animals [4]. Since many gene cassette arrays of integrons contain antimicrobial resistance (AMR) factors, the horizontal transfer of integrons through plasmids and transposons has been found to play an important role in the dissemination of AMR genes and development of multi-resistance in enteric tract, which will be a great health concern [7].

In fact, the main aims of the current study were to determine the prevalence of class I and II integrons and to characterize integron-associated gene cassette arrays in commensal E. coli from human and animal sources in IRI. In addition to the main aims, we aimed to determine the clonality of isolates and to evaluate the applicability of (GTG) $)_{5}$-PCR for differentiating and source tracking of the $E$. coli isolates from different hosts.

\section{Methods}

\section{Samples collection}

In this cross-sectional study, in August 2015, the authors collected the faecal samples from four species: human participants from Kavosh Medical Laboratory (located in Alborz province), chicken, cattle and sheep. Chicken enteric specimens were obtained from private animal breeding farm Qadir in Karaj city (suburb of Alborz province with geographic coordinate of 35.8840059, 50.9716793), while sheep and cattle enteric samples were collected from private facility Raeesi located in Zavvareh city (suburb of Isfahan province with geographic coordinate of 33.449974, 52.490830). Since faecal samples were collected from living animal, no animal was sacrificed.
Before sampling, oral and written information about the study was given to the human participants and owners of breeding farm and facility and an informed consent was obtained. Furthermore, Demographic data about the antibiotics consumptions were recorded. Human participants, cattle and sheep did not take any antibiotic for at least 4 weeks but chicken were fed fosbac (antibiotic for the treatment of systemic and respiratory bacterial diseases caused), trimethoprim-sulphamethoxazole, and oxytetracycline (to increase weight gain and feed conversion ratio in chickens).

For animal sampling, following autoclaving swabs in the capped tubes, they were inserted into the cloaca and rectum of animals in such a manner as to insure the collection of faecal material. The swabs and adhering faecal material were then placed in the tube and quickly shipped to laboratory. However, as mentioned before, human faecal samples were obtained by the participants who referred to Kavosh Medical Laboratory.

Following sampling, a total of 200 faecal samples (50 samples from either of species) were collected and shipped to the central laboratory of Alborz province water and wastewater Company for isolation of E. coli.

\section{Bacterial isolates}

To isolate E. coli, faecal samples were inoculated to lauryl sulphate tryptose (LST) broth (Merck KGaA) followed by E. coli (EC) broth (Merck KGaA) at $44.5^{\circ} \mathrm{C}$ and streaked on eosin methylene blue agar (EMB) agar (Merck KGaA). Colonies showing metal sheen were considered as presumptive $E$. coli isolates and were subjected to IMViC (Merck KGaA), glucuronidase and tryptophanase tests for final confirmation [8].

\section{Antimicrobial susceptibility testing}

Phenotypical antibiotic susceptibility was tested applying Pad tan Teb (Tehran, Iran) disks by Kirby-Bauer disk diffusion method on Mueller-Hinton agar plates according to the guidelines of Clinical and Laboratory Standards Institute [9]. A panel of 24 antibiotic discs were used as follows: ceftazidime $(30 \mu \mathrm{g})$, cefotaxime $(30 \mu \mathrm{g})$, ceftriaxone $(30 \mu \mathrm{g})$, ceftizoxime $(30 \mu \mathrm{g})$, cephalothin $(30 \mu \mathrm{g})$, cefazolin $(30 \mu \mathrm{g})$, cephalexin $(30 \mu \mathrm{g})$, trimethoprim/sulfamethoxazole $(25 \mu \mathrm{g})$, amoxicillin/clavulanic $(20 / 10 \mu \mathrm{g})$, piperacillin $(100 \mu \mathrm{g})$, ampicillin. $(10 \mu \mathrm{g})$, streptomycin $(10 \mu \mathrm{g})$, tobramycin $(100 \mu \mathrm{g})$, Amikacin $(30 \mu \mathrm{g})$, kanamycin $(30 \mu \mathrm{g})$, neomycin $(30 \mu \mathrm{g})$, gentamycin. $(10 \mu \mathrm{g})$, norfloxacin $(10 \mu \mathrm{g})$, ciprofloxacin $(5 \mu \mathrm{g})$, nalidixic acid $(30 \mu \mathrm{g})$, levofloxacin $(5 \mu \mathrm{g})$, chloramphenicol $(10 \mu \mathrm{g})$, tetracycline $(10 \mu \mathrm{g})$, and doxycycline $(10 \mu \mathrm{g})$. Isolates resistant to at least one antimicrobial agent were tested for the presence of class I and II integrons genes by polymerase chain reaction (PCR). 


\section{DNA extraction and PCR assay}

To extract the genomic DNA, bacterial cells were centrifuged at 2500 revolutions per minute (rpm) for $15 \mathrm{~min}$ discarding the supernatant, following manufacturer's protocol (Bioneer's AccuPrep ${ }^{\circledR}$ Genomic DNA Extraction Kit); DNA from all isolates was extracted.

To detect class I and II integrases and to develop a duplex PCR assay, two sets of primer were designed using Allele ID v7.6 software (PREMIER Biosoft, United States). The sequences and amplicons sizes of the primer sets are shown in Table 1. To validate the primer sets, two strains harbouring class I and II integrase genes were obtained from Baqiyatallah University of Medical Sciences, Molecular Biology Research Center, Tehran, Iran.

The gene amplification protocol was performed by Applied Biosystems instruments (ABI) verity 96 well thermal cycler with the temperature profile as follows: initial denaturation $\left(94{ }^{\circ} \mathrm{C}\right.$ for $\left.5 \mathrm{~min}\right)$, followed by 30 cycles of denaturation $\left(94{ }^{\circ} \mathrm{C}\right.$ for $20 \mathrm{~s}$ ), annealing (30 s at $\left.60{ }^{\circ} \mathrm{C}\right)$, and extension $\left(72{ }^{\circ} \mathrm{C}\right.$ for $\left.1 \mathrm{~min}\right)$; and then a final extension $\left(72{ }^{\circ} \mathrm{C}\right.$ for $\left.10 \mathrm{~min}\right)$. Isolates carrying class I and II integrase genes were further characterized through PCR for variable regions under the conditions described previously $[10,11]$. Each cassette gene PCR product with a distinctive size was sequenced by Bioneer Sequencing Service. PCR products of the same size were restricted with FastDigest RsaI (Thermo Scientific) and HinfI (Thermo Scientific) enzymes. Two representative products of each distinct restriction fragment length polymorphism were purified by AccuPrep ${ }^{\circledR}$ PCR Purification Kit (Bioneer, South Korea). Contiguous sequences were created from single sequence reads by using the MEGA 5 sequence assembly program and compared with GenBank $^{\circledR}$ (http://www.ncbi.nlm.nih.gov/genbank).

\section{Table 1 Primer sets used for amplification of class I and II integrons}

\begin{tabular}{|c|c|c|}
\hline Gene target & Sequence $\left(5^{\prime}-3^{\prime}\right)$ & References \\
\hline Int I. F & TCTCGGGTAACATCAAGG & This study \\
\hline Int I. R & GTTCTTCTACGGCAAGGT & This study \\
\hline Int II.F & $\begin{array}{l}\text { CACGGATATGCGACA } \\
\text { AAAAGGT }\end{array}$ & This study \\
\hline Int II.R & $\begin{array}{l}\text { GTAGCAAACGAGTGA } \\
\text { CGAAATG }\end{array}$ & This study \\
\hline $\begin{array}{l}\text { Class I integron variable } \\
\text { region }\end{array}$ & GGCATCCAAGCAAG & Levesque et al. [9] \\
\hline $\begin{array}{l}\text { Class I integron variable } \\
\text { region }\end{array}$ & AAGCAGACTTGACCTGA & Levesque et al. [9] \\
\hline $\begin{array}{l}\text { Class II integron variable } \\
\text { region }\end{array}$ & $\begin{array}{l}\text { GATGCCATCGCAAGTACG } \\
\text { AG }\end{array}$ & White et al. [10] \\
\hline $\begin{array}{l}\text { Class } \| \text { integron variable } \\
\text { region }\end{array}$ & $\begin{array}{c}\text { CGGGATCCCGGACGGC } \\
\text { ATGCACGATTTGTA }\end{array}$ & White et al. [10] \\
\hline
\end{tabular}

\section{Statistical analysis}

The SPSS software (version 19) was used for statistical analysis. The association between the presence of $d f r$ cassette array (in both class I and II) and trimethoprim/ sulfamethoxazole (SXT) resistance, in addition to aad cassette array (in both class I and II) and streptomycin resistance were determined by $\chi^{2}$ or Fisher's exact test. A $p$ value of $<0.05$ was considered statistically significant.

\section{Rep-PCR fingerprinting}

$(\mathrm{GTG})_{5}$-PCR was applied for molecular fingerprinting of the isolates carrying variable regions of integrons under the conditions described before [12]. Gel images were normalized, and fingerprints were assigned to isolates, with Bio-Rad's Image Lab ${ }^{\mathrm{TM}} 4.0$ software. For cluster analysing, the data were converted to a binary matrix and using Mesquite (version 2.75) and PAUP (version 4.beta 10) softwares, similarity trees were generated using the unweighted-pair group method (UPGMA) using average linkages on the basis of $80 \%$ similarity.

\section{Results}

\section{Bacterial isolates}

Following standard E. coli isolation procedure, 200 isolates (one isolate per faecal sample) were collected and included in the present study.

\section{Antimicrobial resistance and integrons cassette arrays}

Antibiotic susceptibility results showed, 136 isolates were MDR (multidrug-resistant). As shown in Table 2, fourteen isolates were resistant to only one antibiotic category, while 136 isolates were resistant to more than two categories (MDR isolates). The number of MDR isolates from chicken, human, cattle, and sheep were 50, 50, 48 and 38, respectively. Of the $136 \mathrm{E}$. coli isolates, 55 isolates carried IntI and 19 isolates carried IntII, while nine isolates carried both classes. Class I integrase gene was detected in $50 \%(25 / 50), 38 \%(19 / 50), 6 \%(3 / 50)$ and $16 \%(8 / 50)$, while class II integrase gene was detected in $26 \%(13 / 50), 8 \%(4 / 50), 0 \%(0 / 50)$ and $4 \%(2 / 50)$ of chicken, human, cattle and sheep isolates, respectively. Among the isolates, $14 \%(7 / 50)$ of chicken and $4 \%$ $(2 / 50)$ of sheep harboured both classes of integrase genes simultaneously.

Following sequencing and comparing with GenBank, nine and four different gene cassette arrays were found in classes I and II integrons, respectively (Tables 3, 4). However, in six class I integron positive and three class II integron positive isolates, the cassette arrays could not be detected by PCR.

Based on statistical analysing, it could be inferred that there was a significant association between $d f r$ cassette arrays and SXT resistance $(p<0.001)$ as well as the 
Table 2 Sources and the number of resistant isolates to antimicrobial categories

\begin{tabular}{|c|c|c|c|c|c|}
\hline No. of resistant categories & No. of chicken isolates & No. of human isolates & No. of cattle isolates & No. of sheep isolates & Sum \\
\hline Resistant to 7 categories & 0 & 0 & 0 & 0 & 0 \\
\hline Resistant to 6 categories & 11 & 0 & 1 & 1 & 13 \\
\hline Resistant to 5 categories & 17 & 6 & 0 & 0 & 23 \\
\hline Resistant to 4 categories & 10 & 12 & 7 & 4 & 33 \\
\hline Resistant to 3 categories & 9 & 22 & 23 & 13 & 67 \\
\hline Resistant to 2 categories & 3 & 10 & 17 & 20 & 50 \\
\hline Resistant to 1 category & 0 & 0 & 2 & 12 & 14 \\
\hline Resistant to 0 category & 0 & 0 & 0 & 0 & 0 \\
\hline Resistant to 2 or more categories & 47 & 40 & 31 & 18 & 136 \\
\hline
\end{tabular}

Table 3 Gene cassette arrays of class I integrons in E. coli from different species

\begin{tabular}{|c|c|c|c|c|c|}
\hline Species/cassette array & $\begin{array}{l}\text { No. }(\%) \text { of the human } \\
\text { isolates carrying gene } \\
\text { cassette array }\end{array}$ & $\begin{array}{l}\text { No. }(\%) \text { of the chicken } \\
\text { isolates carrying gene } \\
\text { cassette array }\end{array}$ & $\begin{array}{l}\text { No. }(\%) \text { of the sheep } \\
\text { isolates carrying gene } \\
\text { cassette array }\end{array}$ & $\begin{array}{l}\text { No. }(\%) \text { of the cattle } \\
\text { isolates carrying gene } \\
\text { cassette array }\end{array}$ & Total $^{2}$ \\
\hline dfrAl & $1(2)$ & $4(8)$ & $0(0)$ & $1(2)$ & 6 \\
\hline dfra5 & $0(0)$ & $3(6)$ & $1(2)$ & $0(0)$ & 4 \\
\hline dfrat & $1(2)$ & $2(4)$ & $0(0)$ & $0(0)$ & 3 \\
\hline dfrA12 & $2(4)$ & $3(6)$ & $1(2)$ & $1(2)$ & 7 \\
\hline aadAl & $3(6)$ & $10(20)$ & $4(8)$ & $1(2)$ & 18 \\
\hline aadA4 & $0(0)$ & $2(4)$ & $1(2)$ & $0(0)$ & 3 \\
\hline dfrA17-aadA1 & $0(0)$ & $2(4)$ & $0(0)$ & $0(0)$ & 2 \\
\hline $\operatorname{aad} A 1-a a d B$ & $1(2)$ & $2(4)$ & $0(0)$ & $0(0)$ & 3 \\
\hline dfrA12-orff-aadA2 & $0(0)$ & $2(4)$ & $1(2)$ & $0(0)$ & 3 \\
\hline Total & $8(16)$ & $30(60)$ & $8(16)$ & $3(6)$ & 49 \\
\hline
\end{tabular}

a The number of the isolates carrying intl, is 55 , however, in six class I integron positive isolates, the cassette arrays could not be detected by PCR

Table 4 Gene cassette arrays of class II integrons in E. coli from different species

\begin{tabular}{lllll}
\hline Species/cassette array & $\begin{array}{l}\text { No. (\%) of the human } \\
\text { isolates carrying gene } \\
\text { cassette array }\end{array}$ & $\begin{array}{l}\text { No. (\%) of the chicken } \\
\text { isolates carrying gene } \\
\text { cassette array }\end{array}$ & $\begin{array}{l}\text { No. (\%) of the sheep } \\
\text { isolates carrying gene } \\
\text { cassette array }\end{array}$ & $\begin{array}{l}\text { No. (\%) of the cattle } \\
\text { isolates carrying gene } \\
\text { cassette array }\end{array}$ \\
\hline dfrA1 & $1(2)$ & $1(2)$ & $2(4)$ & $0(0)$ \\
dfrA1-sat2-aadA1 & $0(0)$ & $2(4)$ & $1(2)$ & $1(2)$ \\
dfrA1-sat1-aadA1 & $1(2)$ & $3(0)$ & $0(0)$ & $0(0)$ \\
at-sat1-aadA1 & $1(2)$ & $2(4)$ & $0(0)$ & $1(2)$ \\
Total & $3(6)$ & $8(16)$ & $3(6)$ & $2(4)$ \\
\hline
\end{tabular}

a The number of the isolates carrying intll, is 19 , however, in three class II integron positive isolates, the cassette arrays could not be detected by PCR

resistance against the streptomycin $(10 \mu \mathrm{g})$ which may be conferred by aad cassette arrays $(p<0.002)$.

\section{DNA fingerprinting analysis}

$(\mathrm{GTG})_{5}$ Fingerprints of commensal E. coli isolates carrying gene cassette arrays of class I and class II integrons was determined using the (GTG) $)_{5}$ PCR assay. (GTG) $5^{-}$ PCR of 49 isolates carrying gene cassette arrays of class I integron, yielded complex banding patterns consisting four to twelve bands ranging in size from 555 base pair (bp) to $3300 \mathrm{bp}$. However, (GTG) $)_{5}$-PCR of 14 isolates carrying gene cassette arrays of class II integrons, yielded five to twelve bands ranging in size from 530 to $3200 \mathrm{bp}$. To evaluate the clonal relation, dendrograms were constructed from (GTG) 5 profiles of the isolates (Figs. 1, 2). At a cut off of $80 \%$ similarity, UPGMA clustering separated all the isolates into various clusters. The 49 isolates carrying class I integron were assigned into six major 


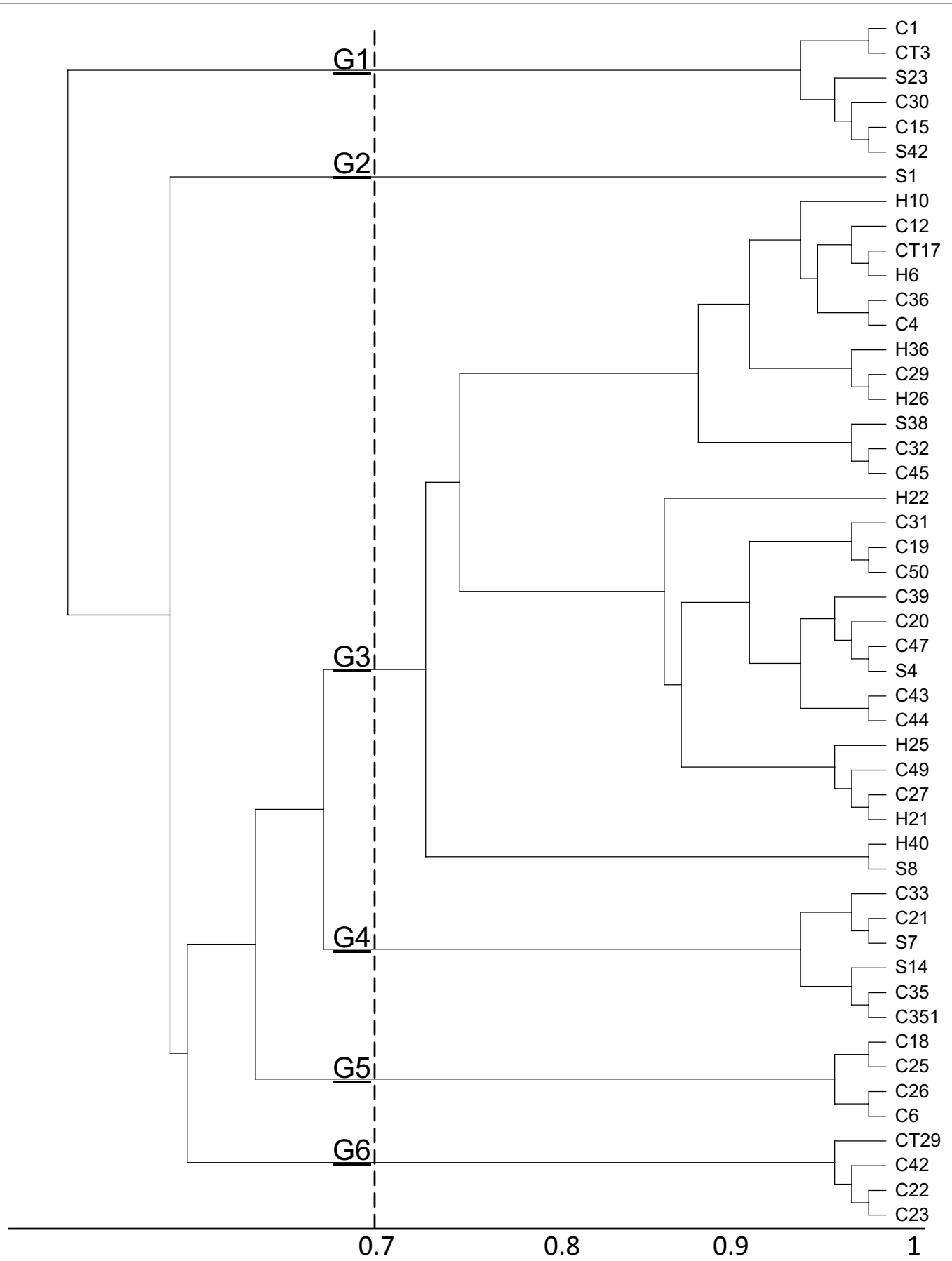

Fig. 1 Dendrogram analysis of DNA fingerprinting obtained from 49 E. coli strains carrying gene cassette arrays of class I integron by (GTG) 5 polymerase chain reaction. The letters and digits shown right side of the dendrogram indicate the code of isolates. $H$ isolate from human; $C$ isolate from chicken; $S$ isolate from sheep; $C T$ isolate from cattle

clusters (G1-G6) and the 14 isolates carrying class II integron were assigned into three major clusters (B1-B3).

Based on the results of the cluster analysis, it was observed that isolates with the same gene cassette arrays were not assigned to a given cluster and in some cases the isolates with different cassette arrays were assigned to the same cluster; therefore, we came to this conclusion that no cassette array could be attributed to a specific (GTG) 5 cluster.

In addition to the main aims, we analyzed the applicability of the (GTG) $)_{5}$-PCR for differentiating of the host 


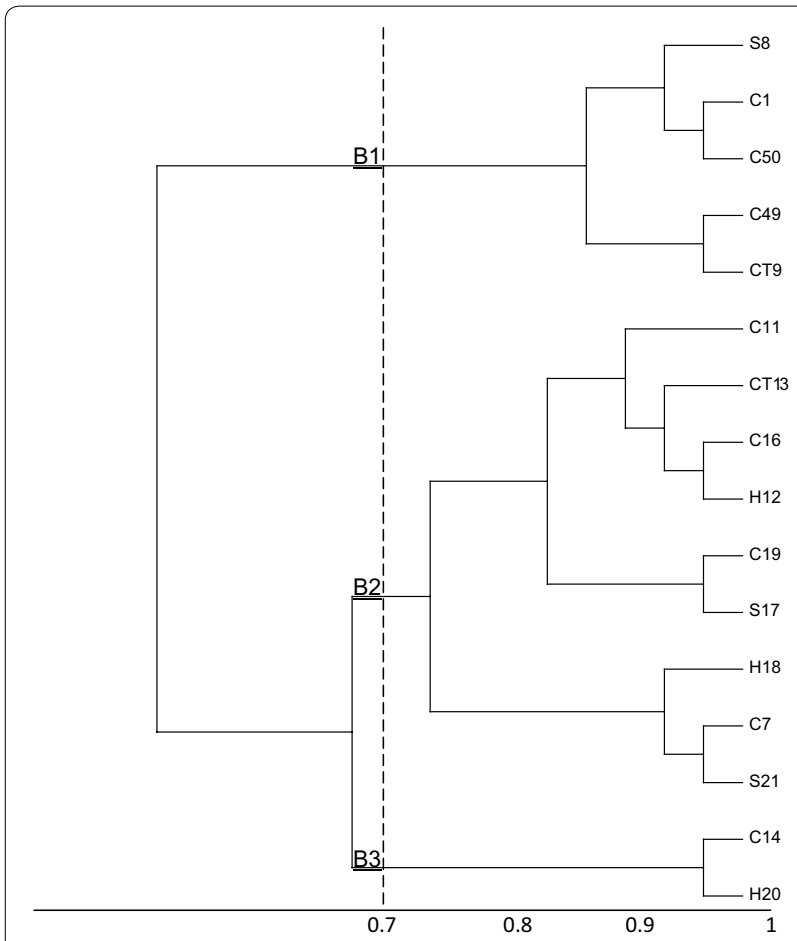

Fig. 2 Dendrogram analysis of DNA fingerprinting obtained from 14 E. coli strains carrying gene cassette arrays of class II integron by (GTG)-PCR. The letters and digits shown right side of the dendrogram indicate the code of isolates. $H$ isolate from human; $C$ isolate from chicken; $S$ isolate from sheep; $C T$ isolate from cattle

animal. As it is observed, E. coli from different sources are assigned in different clusters confirming the low discriminatory power and unsuitability of rep-PCR methods for microbial source tracking.

\section{Discussion}

Antimicrobial resistance in clinical isolates has become a major public health concern [13]. Most studies are directed to clinical isolates because such isolates have probably been subjected to a considerably higher antibiotic selection pressure or to broader spectrum antimicrobials [3]. However, few studies have subjected the AMR and integron prevalence of non-pathogenic commensal bacteria. Integrons are known to be primary source of transferable resistance genes and are suspected to serve as reservoirs of antimicrobial resistance genes within microbial populations $[14,15]$. The present study characterized class I and II integrons and their gene cassettes arrays conferring resistance to several categories of antibiotics in commensal $E$. coli isolates from different species. Of the $200 E$. coli isolates from different species, 136 isolates were MDR, 55 isolates carried class I, 19 isolates carried class II, and 9 isolates carried both of the classes. The distribution of gene cassette arrays among human, sheep, and cattle isolates was similar (Tables 3, 4), except from the chicken isolates. Our demographic data showed among the species, just chicken were fed fosbac, trimethoprim-sulphamethoxazole, and oxytetracycline, both for treatment and as growth factors. Therefore, it is not surprising to observe higher integrons prevalence $(50 \%$ for class I, $26 \%$ for class II, and $14 \%$ for both classes) and more MDR isolates in E. coli from chicken (100 \% MDR).

Many gene cassette arrays able to confer resistance to several antimicrobial classes have been described in class I and II integrons, but those more frequently found are $d f r A, \operatorname{aad} A$, and, for class II integrons, sat $[16,17]$. Our PCR results showed, $d f r$ and $a a d$ were the most prevalent genes cassette arrays which were in agreement with Daikos et al. [18]. Aminoglycoside adenylyl transferases encoded by aad family cassette arrays causes streptomycin/spectinomycin resistance, considering the Table 5 , we found a significant association between isolates carrying family of aad cassette arrays and phenotypically resistance against streptomycin. The other common resistance was observed against trimethoprim/sulfamethoxazole (SXT), which could be explained by $d r f$ gene cassette arrays, because these arrays encode for dihydrofolate reductase enzymes that can yield to trimethoprim resistance. Considering the demographic data of drug consumption as well as drug resistance, the hypothesis of antibiotic mediated resistance could be deduced, because the chicken was the only species which received SXT and it is observed that the $d f r$ cassette arrays $(d f r A 1, d f r A 5$, dfrA7, dfrA12, dfrA17, dfrA12-orfF-aadA2, and dfrA1sat-aadA1) and consequently resistance to SXT, were much more prevalent in this species [19].

As mentioned before, the phenotypic resistance to a specific antibiotic was observed in most of the isolates carrying the corresponding gene cassette which was in agreement with Hall et al. [19]; Barlow et al. [20]; Kor et al. [21], and Li et al. [22]. However, it was also evident that some integron-carrying organisms had reduced susceptibility not only to antimicrobial agents for which the respective gene cassettes were contained in but also to other classes of agents for which no or very little number of genes were contained within the integrons [23].

Except from trimethoprim/sulfamethoxazole and streptomycin, the other proportionally high resistance was against ampicillin, but as listed in the Table 4, ampicillin resistance was completely distributed among the isolates carrying cassette arrays, indicating the ineffectiveness of the integrons for ampicillin resistance. Apparently resistance mechanisms or a considerable number of antibiotic resistance genes were located outside the integrons either on chromosomes or plasmids [6], therefore, not all the resistance profile of the isolates could be explained by the expression of the gene cassettes found 


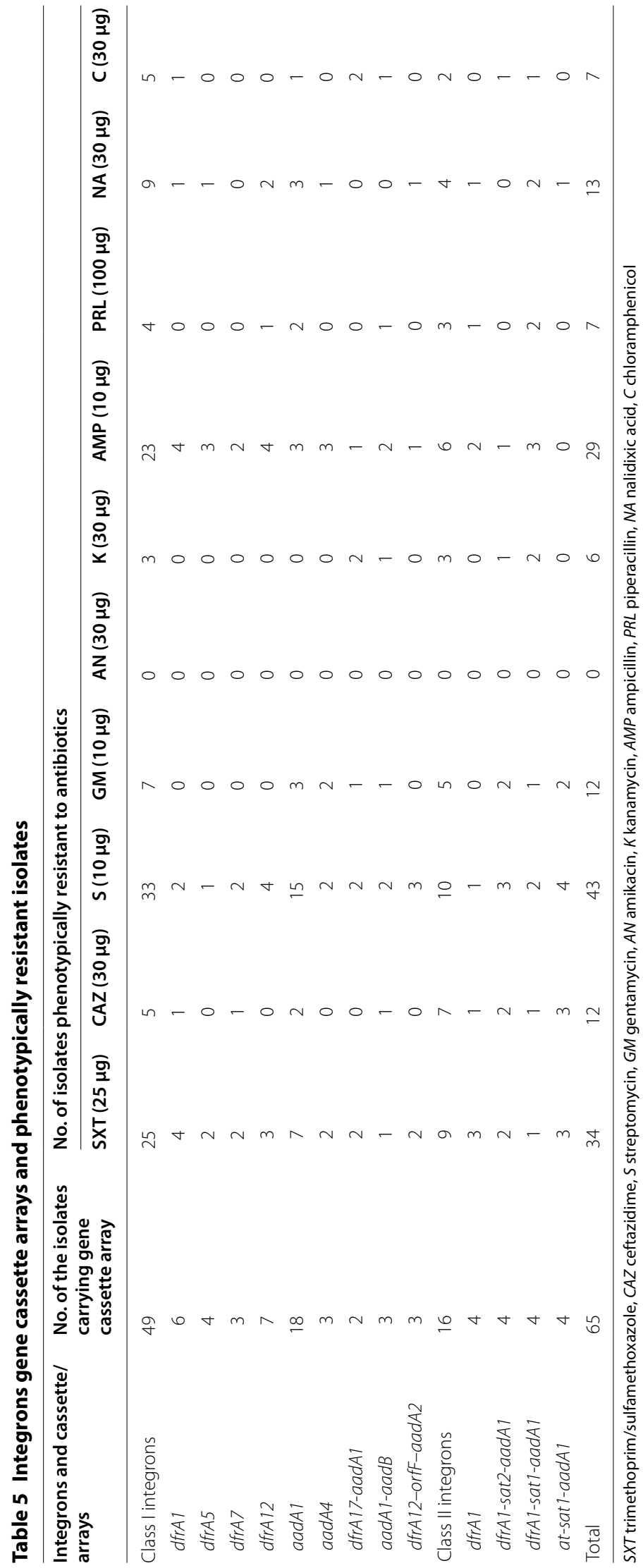


within the integrons [24]. Nevertheless, some isolates carrying integrons were susceptible to the corresponding antibiotic. This finding may be explained by the lack of expression of gene cassettes contained in integrons, as described by Kim et al. [24].

Based on our results, resistance against ceftazidime, gentamycin, amikacin, kanamycin, piperacillin, nalidixic acid and chloramphenicol were not significance and cannot be attributed to the integrons. However, Moghaddam et al. identified all of $E$. coli strains isolated from human urine to be multi-drug resistant and PCR analysis revealed that $97 \%$ of strains carried IntI1 gene [25]. In another study, Tajbakhsh et al. reported that all E. coli strains isolated from different fish fields of Chaharmahal Va Bakhtiari, Iran, were multidrug resistant and $100 \%$ resistance against the ciprofloxacin, chloramphenicol, gentamycin, ampicillin and tetracycline was observed [26]. Since fish field aquacultures, as an unselective media, can receive all kinds of contaminations, the antimicrobial resistance of their report can be generalized to the public health of the community, confirming the severity of antimicrobial resistance among commensal bacteria in Iran which can be explained by high consumption of antibiotics [26]. It is noteworthy to mention that based on available data, consumption of antibiotics in livestock and poultry in Iran is higher than developed countries [27].

Our results confirmed Kang's et al. survey in which commensal E. coli isolated strains from enrofloxacin and norfloxacin medicated poultry were compared to $E$. coli from swine, which were not fed by the mentioned above agents, whereby they found the poultry-originated $E$. coli to be much more resistant than the swine ones because of higher prevalence of dfrA12-orfFaadA2 gene cassette array [28]. These results warn the increasing rate of antibiotic resistance because of antibiotic therapy.

As a result of universal intensive chicken antibiotic feeding, the rate of AMR and integrons prevalence were to some extent similar worldwide. Cavicchio et al. isolated 299 E. coli from avian source and found class I and II, in 49.8 and $10.4 \%$ of the samples while thirteen strains (4.3\%) were positive for both classes [23]. Our molecular results are also comparable to Cavicchio et al. because as they reported, the most common gene cassette arrays identified in class I integron-positive isolates belonged to the aadA (90/149 isolates, $60.4 \%)$ and the dfrA (50/149 isolates, $33.6 \%$ ) gene families, with 5 and 4 different variants, respectively. However, the prevalence of $\operatorname{aad} A$ and $d f r A$ cassette arrays in class II integrons are incompatible to our results, because Cavicchio et al. identified aadA and $d f r A$ in 67.7 and $64.5 \%$ of the class II integron positive isolates [23].
Elizabeth et al. studied E. coli isolates from chicken litter and found class I integron genes in $52.63 \%$ of the isolates which is compatible to our results [29]. Furthermore, they found $d f r A 1$ and $a a d A 1$ as the most prevalent gene cassette arrays.

Vasilakopouloue et al. [30] evaluated the prevalence of class I integron and gene cassettes arrays in E. coli of poultry and human and found the integron carriage rate for poultry isolates was $49.2 \%$, for hospital isolates was $26.2 \%$ and for healthy people was $11.1 \%$. While aad and $d f r$ families were the most prevalent cassette arrays. Vasilakopouloue's survey confirmed our results (poultry integron rate) and showed a difference between AMR of hospitalized and healthy people which can be attributed to drug consumption by hospitalized patients.

Karczmarczyk et al. studied molecular characterization of 100 multidrug-resistant E. coli isolates from Irish Cattle Farms [31]. In their study, Karczmarczyk et al. found twenty-seven $(27 \%)$ isolates harboured class I integrase (which is higher than class I integron rate in $E$. coli from cattle included in our study), while the variable regions of these integrons contained $\operatorname{aad} A 12$, $\operatorname{aadB}$ aadA1, blaOXA-30-aadA1, dfrA1-aadA1, and dfrA7. Class II integrons were identified less frequently (4\%) and contained the gene cassette array dfrA1-sat1-aadA1. Moreover, Karczmarczyk et al. found high resistance of streptomycin (100\%), tetracycline (99\%), ampicillin $(82 \%)$, and sulfonamide (98\%) which was approximately similar to the results reported by Pourtaghi et al. in E.coli isolated from calves in Iran, except from the sulfonamide. Moreover, Pourtaghi et al. reported the resistance of 91.8, 93, 100 and $73.2 \%$ for streptomycin, tetracycline, penicillin, and sulfonamide respectively [32].

Of course the prevalence of class I integrons investigated by Oosterik et al. is half of our report since they found intI gene in $21.6 \%$ of $E$. coli isolated from poultry faeces; however, in their report there is no demographic record of antibiotic prescription to explain such difference [33].

Following amplifying the variable region of the integrons, six integron class I positive isolates and three integron class II positive isolates produced no amplicons when PCR was repeatedly preformed for amplification of gene cassette arrays. Sunde had the same experience [3]. She could not amplify variable region of class I integrons in $10 \mathrm{intI}$ positive strains as well as Malek et al. who did not manage to amplify the cassette regions of three class I integrons isolates [6]. However, Rearrangements, lack of 3'-conserved segment(s), absence of primer hybridization site(s), or presence of early stop codon may explain such phenomenon [34].

The antibiotic therapy of $E$. coli infections is now threatened by the emergence of antimicrobial resistance. 
The dissemination of resistance is associated with genetic mobile elements, such as plasmids, that may also carry virulence determinants [35]. Despite the difference in the evolution of antimicrobial resistance and virulence factors, they share some common characteristics [35]. From a biological point of view, both processes are necessary for bacteria to survive under adverse conditions. Virulence mechanisms are necessary to overcome host defence systems, and the development of antimicrobial resistance is essential to enable pathogenic bacteria to overcome antimicrobial therapies and to adapt to and survive in competitive and demanding environments [36]. An example of involvement of antimicrobial resistance and virulence can be observed in E. coli ST131 (O25:H4). Producing CTX-M-15 extended-spectrum $\beta$-lactamase (ESBL), this strain has emerged internationally as a multidrug-resistant (MDR) pathogen. Thus, $E$. coli isolates able of producing CTX-M-type ESBL and E. coli ST131 have been found to exhibit a wide array of virulence factors [36]. In a study conducted by Asadi et al. in Iran, statistically significant association between fimH gene and resistance to ciprofloxacin, nalidixic acid, and cotrimoxazole was found as well as the associations between $i b e A$ gene and amikacin, elucidating the role of antimicrobial resistance both on attenuation of antibiotic therapy and augmentation of the pathogenesis [37].

In addition to the study of antibiotic resistance and integrons, we analyzed the genetic diversity and the applicability of the (GTG) ${ }_{5}$-PCR for differentiating of the host animals, while we found it unsuitable for tracking, as the result of high degree of diversity and low intra-species similarity among the E. coli isolates. Furthermore, dendrogram generated by $(\mathrm{GTG})_{5-}$ profiles showed that isolates from different species were distributed in different clusters, confirming inapplicability of (GTG) $)_{5}$-PCR as reliable tracking tool. Although, Dombeck et al., reported BOX-PCR and REP-PCR methods are reliable tools to separate the human E. coli isolates from the nonhuman isolates [38] and Mohapatra et al., noted the acceptable average rate of correct classification (ARCC) of (GTG) $5^{-}$ PCR for E. coli source tracking [39], however, it should be considered that controversial reproducibility of PCR, differences in DNA concentration and thermal condition may lead to produce fake bands or remove weak bands, therefore, questioning the applicability of rep-based PCR for source tracking. For more efficient finger printing and subtyping, it is recommended to apply pulse field gel electrophoresis (PFGE) which is a reliable and highly discriminating method and has been considered to be the "gold standard" of typing methods. Through the establishment of PulseNet [40], use of PFGE has had a major impact on pathogen subtyping and outbreak investigation [41].

\section{Conclusion}

Our findings highlighted the importance of the commensal microflora of animals as a reservoir of transferable genes. We concluded that integrons carrying gene cassettes encoding for antibiotic resistance are significantly present among non-pathogenic commensal $E$. coli, especially from the hosts medicated by antibiotics. Uncontrolled use of antibiotics would increase the numbers of MDR isolates and integrons prevalence, which after a while, it could be a significant public health concern.

\begin{abstract}
Abbreviations
Dhfr: dihydrofolate reductase; aad: aminoglycoside adenylyltransferase determinant; E. coli: Escherichia coli; ETEC: enterotoxigenic E. coli; EHEC: enterohemorrhagic E. coli; EAEC: enteroaggregative E. coli; EIEC: enteroinvasive E. coli; EPEC: enteropathogenic E. coli; MDR: multiple drug resistant; AMR: antimicrobial resistance; IRB: Institutional Review Board; IACUC: Institutional Animal Care and Use Committee; LST: lauryl tryptose; EMB: eosin methylene blue agar; BLAST: blast basic local alignment search tool; PCR: polymerase chain reaction; $\mathrm{ABI}$ : applied biosystems instruments; $\mathrm{SXT}$ : trimethoprim/sulfamethoxazole; PAUP: phylogenetic analysis using parsimony; UPGMA: unweightedpair group method; CAZ: ceftazidime; S: streptomycin; GM: gentamycin; AN: amikacin; K: kanamycin; AMP: ampicillin; PRL: piperacillin; NA: nalidixic acid; C: chloramphenicol.
\end{abstract}

\section{Authors' contributions}

RK designed and supervised the study, analyzed the data and drafted the manuscript. LA assisted in interpretation and presentation of the data and edited the manuscript. Both authors read and approved the final manuscript.

\section{Author details}

${ }^{1}$ Molecular Microbiology, Quality Control Office, Alborz Province Water and Wastewater Company, Karaj, Alborz, Islamic Republic of Iran. ${ }^{2}$ Water Treatment Plant, Tehran Water and Wastewater Supply and Treatment Company, Tehran, Islamic Republic of Iran.

\section{Acknowledgements}

We would like to express our gratitude to Rhonda L. Ackley and Albert Riusech for helpful comments and guidance in the revision.

\section{Competing interests}

The authors declare that they have no competing interests.

\section{Availability of data and materials}

The raw data can be made available to the interested researchers by the authors of this article if requested.

\section{Ethical approval and consent to participate}

Human faecal samples were collected in accordance with the bioethics organizations in Iran (including The Ministry of Health and Medical Education, Office of Study for Humanistic and Islamic Science on Medicine and Medical Ethics). For human faecal samples, Institutional Review Board (IRB) approval was obtained from Tehran University of Medical Sciences.

For animal samples, Permission was obtained from Alborz University of Veterinary Sciences and Institutional Animal Care and Use Committee (IACUC) approved this specific study.

To collect samples, written information about the study was given to the owners of breeding farm and facility and Informed consent was obtained.

Received: 23 June 2016 Accepted: 22 August 2016

Published online: 30 August 2016 


\section{References}

1. Akter S, Islam M, Afreen KS, Azmuda N, Khan SI, Birkeland NK. Prevalence and distribution of different diarrhoeagenic Escherichia coli virulotypes in major water bodies in Bangladesh. Epidemiol Infect. 2013;141:2516-25.

2. Kadlec K, Schwarz S. Analysis and distribution of class 1 and class 2 integrons and associated gene cassettes among Escherichia coli isolates from swine, horses, cats and dogs collected in the BfT-GermVet monitoring study. J Antimicrob Chemother. 2008;62:469-73.

3. Sunde M. Prevalence and characterization of class 1 and class 2 integrons in Escherichia coli isolated from meat and meat products of Norwegian origin. J Antimicrob Chemother. 2005;56:1019-24.

4. Jianyu S, Shi L, Liansheng Y, Zenghuang X, Li X, Shinji Y. Analysisof integrons in clinical isolates of Escherichia coli in China during the last 6 years. FEMS Microbiol Lett. 2006;254:75-80.

5. Canal N, Meneghetti KL, Almeida CPD, Bastos MDR, Otton LM, Corc $\mathrm{G}$. Characterization of the variable region in the class 1 integron of antimicrobial-resistant Escherichia coli isolated from surface water. Braz J Microbiol. 2016:4(7):337-44

6. Malek MM, Amer FA, Allam AA, El-Sokkary RH, Gheith T, Arafa MA. Occurrence of classes I and II integrons in Enterobacteriaceae collected from Zagazig University Hospitals, Egypt. Front Microbiol. 2015;6:601.

7. Matthew TR, Everardo V, Suresh DP. Antimicrobial resistance markers of class 1 and class 2 integron- bearing Escherichia coli from irrigation water and sediment. Emerg Infect Dis. 2003;9:822-6.

8. Roohollah K, Naser H, Mehrouz D. Efficacy evaluation of four different culture and PCR-based methods of Escherichia coli detection in water samples. Adv Environ Biol. 2013;7(9):2689-94.

9. CLSI. Clinical and Laboratory Standards Institute (CLSI): performance standards for antimicrobial susceptibility testing: twenty-second informational supplement M100-S21. Wayne: CLSI; 2012.

10. Levesque $\mathrm{Cl}$, Piche $\mathrm{L}$, Larose $\mathrm{C}$, Roy PH. PCR mapping of integrons reveals several novel combinations of resistance genes. Antimicrob Agents Chemother. 1995:39(1):185-91.

11. White PA, Mciver CJ, Rawlinson DW. Integrons and gene cassettes in the Enterobacteriaceae. Antimicrob Agents Chemother. 2001:45:2658-61.

12. Versalovic J, Schneider M, Bruijn F, Lupski J. Genomic fingerprinting of bacteria using repetitive sequence-based polymerase chain reaction. Methods Mol Cell Biol. 1991:5:25-40.

13. Guangchao Y, Yanmei L, Xiaochen $L$, Xihong Z, Yanyan L. Role of integrons in antimicrobial resistance: a review. Afr J Microbiol Res. 2013;7(15):1301-10.

14. Collis C, Kim M, Stokes H, Hall R. Integron-encoded Intl integrases preferentially recognize the adjacent cognate attl site in recombination with a 59-be site. Mol Microbiol. 2002;46:1415-27.

15. Ochman H, Lawrence J, Groisman E. Lateral gene transfer and the nature of bacterial innovation. Nature. 2000;18(405):299-304

16. Partridge S, Tsafnat G, Coiera E, Iredell J. Gene cassettes and cassette arrays in mobile resistance integrons. FEMS Microbiol Rev. 2009;33:757-84.

17. Hall R. Integrons and gene cassettes: hotspots of diversity in bacterial genomes. Ann NY Acad Sci. 2012;1267:71-8.

18. Daikos GL, Kosmidis C, Tassios PT, Petrikkos G, Vasilakopoulou A, Psychogiou M, Stefanou I, Avlami A, Katsilambros N. Enterobacteriaceae bloodstream infections: presence of integrons, risk factors, and outcome. Antimicrob Agents Chemother. 2007;51(7):2366-72.

19. Maurine A, Hall LV, Adrienne TA, Blok BHEM, Paauw A, Fluit AC, Verhoef J. Evidence of extensive interspecies transfer of integron-mediated antimicrobial resistance genes among multidrug-resistant enterobacteriaceae in a clinical setting. J Infect Dis. 2002;186:49-56.

20. Barlow RS, Pemberton JM, Desmarchelier PM, Gobius KS. Isolation and characterization of integron-containing bacteria without antibiotic selection. Antimicrob Agents Chemother. 2004;48:838-42.

21. Kor S-B, Choo Q-C, Chew C-H. New integron gene arrays from multiresistant clinical isolates of members of the Enterobacteriaceae and Pseudomonas aeruginosa from hospitals in Malaysia. J Med Microbiol. 2013;64:412-20
22. Li B, Hu Y, Wang Q, Yi Y, Woo PC, Jing WH. Structural diversity of class 1 integrons and their associated gene cassettes in Klebsiella pneumoniae isolates from a hospital in China. PLOS One. 2013;8(9):e75805.

23. Cavicchio L, Dotto G, Giacomelli M, Giovanardi D, Grilli G, Franciosini MP Trocino A, Piccirillo A. Class 1 and class 2 integrons in avian pathogenic Escherichia coli from poultry in Italy. Poult Sci. 2015;94:1202-8.

24. Kim T, Jeong Y, Cho S, Kim S, Kwon H. Chronological study of antibiotic resistances and their relevant genes in Korean avian pathogenic Escherichia coli isolates. J Clin Microbiol. 2007:45(10):3309-15.

25. Moghaddam MJM, Mirbagheri AA, Salehi Z, Habibzade SM. Prevalence of class I integrons and extended spectrum beta lactamases among multidrug resistant Escherichia coli isolates from North of Iran. Iran Biomed J. 2015;19(4):233-9.

26. Tajbakhsh E, Khamesipour F, Ranjbar R, Ugwu IC. Prevalence of class 1 and 2 integrons in multi-drug resistant Escherichia coli isolated from aquaculture water in Chaharmahal Va Bakhtiari province, Iran. Ann Clin Microbiol Antimicrob. 2015;14:14-37.

27. Aalipour F, Mirlohi M, Jalali M. Determination of antibiotic consumption index for animal originated foods produced in animal husbandry in Iran, 2010. J Environ Health Sci Eng. 2014;12(1):1.

28. Kang HY, Jeong YS, Oh JY, Tae SH, Choi CH, Moon DC, Lee WK, Lee YC, Seo SY, Cho DT, et al. Characterization of antimicrobial resistance and class 1 integrons found in Escherichia coli isolates from humans and animals in Korea. Oxf J Med Health J Antimicrob Chemother. 2005;55:639-44.

29. Ponce-Rivas E, María-Enriqueta, Muñoz-Márquez, Khanc AA. Identification and molecular characterization of class 1 integrons in multiresistant Escherichia coli isolates from poultry litter. Appl Environ Microbiol. 2012;78(12):5444-7.

30. Vasilakopoulou A, Psichogiou M, Tassios LPT, Kosmidis C, Petrikkos G, Roma E, Charvalos E, Passiotou M, Avlami A, Daikos G. Prevalence and characterization of class 1 integrons in Escherichia coli of poultry and human origin. Foodborne Pathog Dis. 2009;6(10):1211-8.

31. Karczmarczyk M, Walsh C, Slowey R, Leonard N, Fanning S. Molecular characterization of multidrug-resistant Escherichia coli isolates from Irish cattle farms. Appl Environ Microbiol. 2011;77(20):7121-7.

32. Pourtaghi $\mathrm{H}$, Sodagari HR. Antimicrobial resistance of enterotoxigenic and non enterotoxigenic Escherichia coli isolated from diarrheic calves in Iran. Int J Enteric Pathog. 2016;4(2):e34557. doi:10.17795/ijep34557.

33. Oosterik LH, Peeters L, Mutuku I, Goddeeris BM, Butaye P. Susceptibility of avian pathogenic Escherichia coli from laying hens in Belgium to antibiotics and disinfectants and integron prevalence. Avian Dis J. 2014;58:271-8.

34. Ramírez M, Piñeiro S. Novel insights about class 2 integrons from experimental and genomic epidemiology. Antimicrob Agents Chemother. 2010:54(2):699-706.

35. Silva GD, Mendonça N. Association between antimicrobial resistance and virulence in Escherichia coli. Virulence. 2012;3:18-28.

36. Beceiro A, Tomás M, Bou G. Antimicrobial resistance and virulence: a successful or deleterious association in the bacterial world? Clin Microbiol Rev. 2013:26(2):185-230.

37. Asadi S, Kargar M, Najafi KSA, Ghorbani-Dalini S. The association of virulence determinants of uropathogenic Escherichia coli with antibiotic resistance. Jundishapur J Microbiol. 2014;7(5):e9936.

38. Dombek PE, Johnson LK, Zimmerley ST, Sadowsky MJ. Use of repetitive DNA sequences and the PCR to differentiate Escherichia coli isolates from human and animal sources. Appl Environ Microbiol. 2000;66:2572-7.

39. Mohapatra BR, Mazumder A. Comparative efficacy of five different rep-PCR methods to discriminate Escherichia coli populations in aquatic environments. Water Sci Technol. 2008;58:537-47.

40. Ribot E, Fair M, Gautom R, Cameron D, Hunter SB, Swaminathan B, et al. Standardization of pulsed-field gel electrophoresis protocols for the subtyping of Escherichia coli 0157:H7, Salmonella, and Shigella for PulseNet. Foodborne Pathog Dis. 2006:3(1):59-67.

41. Fratamico PM, et al. Advances in molecular serotyping and subtyping of Escherichia coli. Front Microbiol. 2016;7:644. 